INTERNATIONAL JOURNAL OF SYSTEMATIC BACTERIOLOGY

Vol. 17, No. 2 April 1967 pp. 139-144

Copyright 1967 by the Iowa State University Press.

\title{
REPORT ON THE ACTIVITY OF THE SUBCOMMITTEE ON TAXONOMY OF THE ACTINOMYCETES
}

The members of the Subcommittee are:

Baldacci, Dr. E., Milan, Italy

Clark, Dr. W.A. (ex officio, ICNB) Rockville, Maryland, U.S. A.

DeVries, Dr. G. A., Baarn, The Netherlands

Gottlieb, Dr. D. (Chairman), Urbana, Illinois, U.S.A.

Hütter, Dr. R., Zurich, Switze rland

Kalakoutskii, Dr. L. V., Moscow, U.S.S.R.

Krasil'nikov, Dr. N. A., Moscow, U.S.S.R.

Küster, Dr. E. (Secretary), Dublin, Ireland

Lechevalier, Dr. H. , New Brunswick, New Jersey, U.S. A.

Locci, Dr. R., Milan, Italy

Okami, Dr. Y., Tokyo, Japan

Prauser, Dr. H., Jena, Germany

Preobrashenskaja, Dr. J.P., Moscow, U.S.S.R.

Pridham, Dr. T. G. , Anaheim, California, U.S.A.

Sanchez-Marroquin, Dr. A., Mexico City, Mexico

Slack, Dr. J.M., Morgantown, West Virginia, U.S. A.

Waksman, Dr. S.A., New Brunswick, New Jersey, U.S. A.

The various meetings and activities of the subcommittee during the VIII International Congress for Microbiology held at Montreal in 1962 have already been reported (Int. Bull. Bact. Nomencl. Taxon. 14:1-3, 1964).

A cooperative project for the characterization and description of type strains (International Streptomyces Project) has been started under the directorship of Dr. E. B. Shirling (Delaware, Ohio) in connection with the Subcommittee on Actinomycetes of the American Society for Microbiology. One hundred and thirty different Streptomyces species have been examined and described using standardized methods by 39 different workers. A second experiment is in progress for the examination of another set of 120 species at 36 laboratories.

A meeting of the subcommittee was held at the IX International Congress for Microbiology in Moscow on July 22, 1966.

Members present were: Drs. Baldacci (represented by Locci), DeVries, Gottlieb, Küster, and Slack. 
Non-members present were: Drs. Gause, Locci, and Preobrashenskaja.

The following report, presented by Dr. Gottlieb, was received on the International Streptomyces Project (ISP):

The first experiment with 140 cultures has already been completed. The second and third experiments, with sets of 120 and 45 species respectively, are in progress. A description of methods used in these experiments has recently been published (Int. J. System. Bacteriol. 16:313, 1966). A shortage of available cultures prevented the completion of the se experiments. A list of species was circulated for which no type strains are available and for which candidates for neotypes are requested. The question of procedure in proposing neotypes has been discussed. It was recommended that names of species should be abandoned for which no neotypes are known or proposed. It was also suggested that the author of a newly described species should ask two colleagues working in the same area of investigation to examine the species in question following the methods of ISP. It is considered that the investigational procedure adopted by the Subcommittee on Streptomycetes are proving successful and that their adoption by other subcommittees should be encouraged. In particular their procedures stress the reexamination of a new species by at least two neutral workers using common methods which should be standardized as far as possible.

A report was received from Dr. Slack on the activity of the Subgroup on the Taxonomy of the Microaerophilic Actinomycetales. Twelve cultures of microaerophilic actinomycetes (species of Actinomyces, Odontomyces and Nocardia) have been distributed to various workers in order to carry out comparative studies on morphology, microcolony morphology, oxygen tole rance, and biochemical reactions. Special studies on cell-wall composition, pathogenicity, antigenicity, and fermentation end-products are in progress. Details and the first results of this cooperative experiment were presented to the Round Table Conference on Actinomycetes held on July 23, 1966, in Moscow.

In a discussion about the color determination of Streptomyces colonies, it was agreed that Tresner's Color Wheels are the most satisfactory color tables for practical use. The point was stressed by Dr. Locci that it should be sufficient to determine the color groups and not the individual color 
shades of this group. The importance of the surface color of the background (white, gray, black) for color determination was mentioned. Two othe $r$ criteria for the characterization of streptomycetes were proposed by Dr. Preobrashenskaja:

(a) Determination of the color of the aerial mycelium by preparing acetone extracts from it and recording the absorption spectra in the visible region, and

(b) measurements of the lengths of the spiny and hairy outgrowths of Streptomyces spores.

A report (see Appendix) was received on the efforts made by the subcommittee to circulate its recommendation for a uniform description of actinomycetes in patents. In the discussion it was suggested that arrangements be made by DeVries to collect published material about the situation in different countries with regard to the description of streptomycetes in patent applications.

On behalf of Dr. Baldacci some documents on the diagnosis of the genus Streptoverticillium and its type species were recommended by the subcommittee to be forwarded to the Judicial Commission. It was explained that only monoverticillate forms exist, and the term "umbelate" was introduced, which is more accurate than biverticillate, as true biverticillates have never been observed.

It was agreed that the ISP type strains should be sent simultaneously to the type-culture collections at Baarn, Moscow, Tokyo, and Washington. CBS, Baarn, will be the official type-culture depository for the ISP Type Culture Collection. The Secretary will ask the type-culture collections in question for methods commonly used for preserving streptomycetes.

It was recommended that two new subgroups within the subcommittee be formed:

(a) Subgroup on the Taxonomy of oligosporic Actinomycetes, and

(b) Subgroup on the Taxonomy of Nocardiae.

The following new members have been elected to the subcommittee: Drs. Kalakoutskii, Lechevalier, Locci, Prauser, and Preobrashenskaja.

Dr. Gottlieb and Dr. Küster were re-elected as Chairman and Secretary respectively. 


\begin{abstract}
APPENDIX
Report by the Subcommittee on Recommendations for Uniform Description of Streptomycetes in Patents
\end{abstract}

In a discussion of the relationship of streptomycetes to patents, three aspects have to be considered:

1. the description of streptomycetes in patents,

2. the validity of these descriptions for taxonomic and nomenclatural purposes, and

3. the deposition of cultures protected by patents and their availability to the public.

1. The Subcommittee's recommendation, which was published in the Int. Bull. Bact. Nomencl. Tax. 13:169 (1963), suggests a minimum set of morphological and physiological criteria to be used in the characterization of streptomycetes. In order to distribute this recommendation as widely as possible, copies of it were sent to 76 patent offices, 25 microbiological societies, and 128 industrial companies which deal with microbial fermentations. Copies were also sent to 35 individuals asking them for information about the situation in their countries. The reply was not very encouraging. Only four societies and seven patent offices acknowledged the receipt of the circular, but without any comment or suggestions. A few agreed to consider our proposal. Helpful information was received from seventeen individuals. One case, the reply from the Danish Patent Office (October 1964), was outstanding. The Scandinavian (Danish, Finnish, Norwegian, Swedish) patent authorities have adopted uniform directions for the handling of patent applications concerning microbiological methods. These directions have been formulated by $T$. Vincents Nissen, who is special adviser to the Danish Patent Authority, and were published in the Danish Patent Journal in February, 1962. A particular paragraph is devoted to the description of streptomycetes and contains a number of the required criteria. A re-evaluation of the directives is in progress, in which our recommendation will be considered. One paragraph seems to be quite interesting and worthwhile quoting:

"Since the description of the organism cannot be regarded as comprising such mutants the characteristics of which differ essentially from the characteristics stated, indications such as the invention is not limited to the application 
of the organism mentioned, but will also comprise the application of natural as well as artificially produced mutants the re of' cannot be allowed."

2. Rule 11 of the International Code of Nomenclature of Bacteria was emended at Montreal (1962) in such a way that "the inclusion of a name or description or both in a patent application or in a patent does not constitute effective publication." At the last subcommittee meeting the emendation was fully endorsed. It is not surprising that this decision has been opposed by many industrial microbiologists. After a long discussion between members of the Judicial Commission of the I. C.N.B. and a group of microbiologists from industry, a proposal was developed in which the last sentence of the emended Rule 11 was changed as follows:

"The inclusion of a name of a new taxon of bacteria in a published patent application or issued patent does not constitute effective publication."

Additionally, the following statement has been appended to Rule 12 of the International Code of Nomenclature of Bacteria (Int. J. Syst. Bacteriol. 16(4):470, 1966):

"The name of a taxon of bacteria not effectively published in a patent application or in an issued patent may be validly published by subsequent publication of a name in conformity with Rule 11, provided such publication is accompanied by a description of the taxon or by reference to a previously and effectively published description. The date of issuance of the patent shall be included and is recognized as the date of publication."

3. The last question regarding the availability of cultures of new species described in a patent and deposited in a permanently established type-culture collection has not been satisfactorily settled. As long as no internationally uniform regulations exist in handling cultures deposited by industrial companies, the whole situation is still disappointing and dissatisfying. In some countries the free distribution of commercial strains is restricted even afte $r$ the patent has been granted and issued.

The problem of patents dealing with microorganisms has already been discussed and published by L.J. Robbins: 
Patents for Microbiological Transformations - an International Problem. (J. Patent Off. Soc. 152:830-848, 1960).

\author{
E. Küster \\ Secretary
}

